\title{
Yersinia ruckeri biotype 2 isolates from mainland Europe and the UK likely represent different clonal groups
}

\author{
Richard W. Wheeler ${ }^{1,2,6}$, Robert L. Davies ${ }^{2}$, Inger Dalsgaard ${ }^{3}$, Jose Garcia ${ }^{4,7}$, \\ Timothy J. Welch ${ }^{5}$, Sariqa Wagley ${ }^{1}$, Kelly S. Bateman ${ }^{1}$, David W. Verner-Jeffreys ${ }^{1, *}$ \\ ${ }^{1}$ Cefas Weymouth Laboratory, The Nothe, Barrack Road, Weymouth, Dorset DT4 8UB, UK \\ ${ }^{2}$ Division of Infection and Immunity, Glasgow Biomedical Research Centre, University of Glasgow, 120 University Place, \\ Glasgow G12 8TA, UK \\ ${ }^{3}$ Fish Disease Laboratory, National Institute of Aquatic Resources, Technical University of Denmark, Stigbøjlen 4 , \\ 1870 Frederiksberg $C$, Denmark \\ ${ }^{4}$ Universidad Complutense de Madrid, Madrid, Spain \\ ${ }^{5}$ USDA/ARS National Center for Cool and Cold Water Aquaculture, 11861 Leetown Rd., Kearneysville, \\ West Virginia 25430, USA \\ ${ }^{6}$ Present address: F 18 Foster Lab, Firth Court, Western Bank, University of Sheffield, Sheffield S10 2TN, UK \\ ${ }^{7}$ Present address: Dpto. Sanidad Animal, Fac. Veterinaria-UCM Avda, Puerta de Hierro s/n, 28040 Madrid, Spain
}

\begin{abstract}
There have been increased reports of outbreaks of enteric redmouth disease (ERM) caused by Yersinia ruckeri in previously vaccinated salmonids in Europe, with some of these outbreaks being attributed to emergent non-motile, Tween 80-negative, biotype 2 isolates. To gain information about their likely origins and relationships, a geographically and temporally diverse collection of isolates were characterised by serotyping, biotyping, pulsed-field gel electrophoresis (PFGE) and outer membrane protein (OMP) profiling. A total of 44 pulsotypes were identified from 160 isolates by PFGE, using the restriction enzyme NotI. Serotype O1 isolates responsible for ERM in rainbow trout in both the US and Europe, and including biotype 2 isolates, represented a distinct subgroup of similar pulsotypes. Biotype 2 isolates, responsible for outbreaks of the disease in rainbow trout in the UK, Denmark and Spain, had different pulsotypes, suggesting that they represented different clones that may have emerged separately. Danish biotype 2 isolates recovered since 1995 were indistinguishable by PFGE from the dominant biotype 1 clone responsible for the majority of outbreaks in Denmark and the rest of mainland Europe. In contrast, US biotype 2 isolate YRNC10 had an identical pulsotype and OMP profile to UK biotype 2 isolates, suggesting that there had been exchange of these isolates between the UK and the US in the past. UK Atlantic salmon isolates were genetically and serologically diverse, with 12 distinct pulsotypes identified among 32 isolates.
\end{abstract}

KEY WORDS: Yersinia ruckeri · Pulsed-field gel electrophoresis · PFGE - Enteric redmouth disease · ERM $\cdot$ Biotype $\cdot$ Emerging strain

\section{INTRODUCTION}

The Gram-negative enterobacterium Yersinia ruckeri is the aetiological agent of enteric redmouth disease (ERM), which is a chronic to acute haemorrhagic septicaemia of salmonid fish species, particularly in rain- bow trout Oncorhynchus mykiss (Walbaum). ERM outbreaks are a serious economic concern, as rainbow trout are one of the most widely farmed salmonid species, with global production being second only to that of the Atlantic salmon (Hardy et al. 2000). ERM has been successfully controlled by vaccination with 
monovalent killed whole cell commercial vaccines, generally based on the Hagerman type strain (Horne \& Barnes 1999). However, reports of ERM vaccine breakdown have emerged in Europe and the USA, which are attributed to biotype 2 (Tween 80-negative, nonmotile) isolates of $Y$. ruckeri (Austin et al. 2003, Fouz et al. 2006, Arias et al. 2007). Biotype 2 isolates were first described as having caused the disease in UK rainbow trout by Davies \& Frerichs (1989).

Farmers have also reported increasing mortalities due to yersiniosis of UK Atlantic salmon Salmo salar (L.); however, there are limited published studies regarding yersiniosis of this species (Bullock et al. 1976, Bruno \& Munro 1989). Nevertheless, farmed Atlantic salmon fry in the major production areas of Europe (Scotland, Ireland and Norway) and Chile are routinely vaccinated with commercial rainbow trout ERM vaccines or autologous preparations (Bravo \& Midtlyng 2007, L. A. Laidler pers. comm.). In Chile alone, up to 140 million salmon $\mathrm{yr}^{-1}$ were vaccinated against yersiniosis between 1999 and 2003 (Bravo \& Midtlyng 2007).

Yersinia ruckeri is a highly clonal and biochemically homogeneous species (Schill et al. 1984, Stevenson \& Airdrie 1984, Daly et al. 1986, Pyle et al. 1987, Davies 1991a, Garcia et al. 1998). A single serogroup (serovar 1 or heat-stable O1 antigen) is responsible for most outbreaks in rainbow trout farmed worldwide (Stevenson \& Airdrie 1984, Davies 1991a). This can be further subdivided by biotype and outer membrane protein (OMP) type into 6 major clonal groups. Clonal groups 2 and 5 are predominantly associated with rainbow trout ERM (Davies 1991a). Clonal group 5 isolates, which include the Hagerman type strain (ATCC 29473), are the most prevalent cause of ERM in mainland Europe and the US, while clonal group 2 isolates are responsible for ERM in the UK (Davies 1991a). The virulent nature of $\mathrm{O} 1$ clonal groups 2 and 5 isolates was correlated with resistance to serum killing and the presence of a $75 \mathrm{kDa}$ plasmid, which are characteristics that are absent in the remaining $\mathrm{O} 1$ clonal groups not reported as agents of rainbow trout ERM (Guilvout et al. 1988, Davies 1991c, Garcia et al. 1998).

The existing typing scheme (Davies 1991a) is insufficient for investigating the genetic relatedness of isolates. The present study reports the development of a pulsed-field gel electrophoresis (PFGE) method to supplement the Davies (1991a) typing scheme and investigate the relationship between highly similar Yersinia ruckeri clones responsible for recent ERM outbreaks among salmonids. In particular, it is shown that emergent biotype 2 strains in the UK and Europe conform to different PFGE pulsotypes (pt), suggesting that these isolates may have evolved independently, rather than as a result of cross-border introduction of strains.

\section{MATERIALS AND METHODS}

Bacterial strains and growth conditions. A total of 160 Yersinia ruckeri isolates from different countries collected over a $>30 \mathrm{yr}$ period were included in this study (Table 1). These included 14 reference strains representing each of the various groups identified in the typing scheme described by Davies (1991a; Table 2), the species type strain (Hagerman strain ATCC 29473) and a representative of the new UK rainbow trout biogroup (EX5) described by Austin et al. (2003). Isolates were initially confirmed as Y. ruckeri using standard biochemical tests (Davies \& Frerichs 1989). These included initially determining that the isolates were fermentative Gram-negative, catalase positive, cytochrome oxidase-negative, slightly curved rods, and also using results from testing with the API 20E system (Biomerieux). The bacterial isolates were cryopreserved at $-70^{\circ} \mathrm{C}$ on Protect Beads (Technical Service Consultants), following the manufacturer's instructions. Cryopreserved cultures of Y. ruckeri were revived and grown on tryptone soya agar (TSA; Oxoid) at $22^{\circ} \mathrm{C}$ for $48 \mathrm{~h}$ prior to testing.

Biotyping. Strains were checked for motility by dark-field microscopy of a 'hanging drop' culture (Buller 2004). Ability to hydrolyse Tween 80 (phospholipase activity) was indicated by the presence of clear zones around colonies grown for up to $48 \mathrm{~h}$ at $22^{\circ} \mathrm{C}$ on Tween 80 agar plates (Cowan \& Steel 1993, p. 329).

Table 1. Origin of Yersinia ruckeri strains. Type strains: American Type Culture Collection (ATCC) 29473 Hagerman type strain

\begin{tabular}{|llc|}
\hline $\begin{array}{l}\text { Country } \\
\text { of origin }\end{array}$ & Species of origin & $\begin{array}{c}\text { No. of } \\
\text { isolates }\end{array}$ \\
\hline Australia & Salvelinus fontinalis (Mitchill) & 1 \\
Canada & Oncorhynchus mykiss Walbaum & 1 \\
Denmark & O. mykiss & 50 \\
& Anguilla anguilla L. & 1 \\
& Salmo trutta L. & 1 \\
Finland & Coregonus peled (Gmelin) & 1 \\
& Salmo salar L. & 1 \\
France & O. mykiss & 2 \\
& Psetta maxima L. & 2 \\
Italy & Esox lucius L. & 1 \\
Norway & O. mykiss & 1 \\
Spain & O. mylar & 1 \\
UK & O. mykiss & 3 \\
& S. salar & 52 \\
& Thymallus thymallus (L.) & 32 \\
& S. trutta & 1 \\
USA & Unknown & 3 \\
& O. mykiss & 2 \\
& Oncorhynchus tshawytscha & 3 \\
& (Walbaum) & \\
\hline
\end{tabular}


Table 2. Pulsed-field gel electrophoresis (PFGE) identification of sample strains from the different clonal groupings previously identified by Davies (1991a) based on O-antigen serotype, biotype, and outer membrane protein (OMP) type. Pulsotype as designated in Fig. 1. Also included are isolates EX5, YRNC10, 07029, 07039, and 06076, which were newly characterised as part of this study. nk: exact date of first isolation not known, but prior to 1988. See Table 1 for full generic names

\begin{tabular}{|c|c|c|c|c|c|c|c|}
\hline Pulsotype & Isolate & $\begin{array}{l}\text { Country } \\
\text { of origin }\end{array}$ & Host species & $\begin{array}{l}\text { Year of } \\
\text { isolation }\end{array}$ & $\begin{array}{l}\text { Serotype/ } \\
\text { clonal group }\end{array}$ & Biotype & OMP type \\
\hline 1 & RD34 & UK & O. mykiss & 1990 & $\mathrm{O} 2^{\mathrm{a}}$ & 1 & 1 \\
\hline 4 & RD168 & USA & O. tshawytscha & $\mathrm{nk}$ & $\mathrm{O} 2^{\mathrm{a}}$ & 1 & 2 \\
\hline 8 & 07029 & UK & S. salar & 2005 & $\mathrm{O} 2$ & 1 & 4 \\
\hline 12 & RD150 & Denmark & A. anguilla & 1985 & $O 7^{\mathrm{a}}$ & 1 & 1 \\
\hline 15 & RD22 & Finland & S. salar & $\mathrm{nk}$ & $\mathrm{O} 5^{\mathrm{a}}$ & 1 & 4 \\
\hline 16 & RD154 & Norway & S. salar & 1985 & O1 clonal group $4^{\mathrm{a}}$ & 2 & 2 \\
\hline 19 & 07039 & UK & S. salar & 2006 & $\mathrm{O} 1$ & 1 & 4 \\
\hline 23 & RD194 & Canada & O. mykiss & $\mathrm{nk}$ & $\mathrm{O} 6^{\mathrm{a}}$ & 1 & 2 \\
\hline 26 & RD156 & Australia & S. fontinalis & 1984 & O1 clonal group $1^{\mathrm{a}}$ & 1 & 1 \\
\hline 31 & RD10 & UK & O. mykiss & 1985 & O1 clonal group $2^{\mathrm{a}}$ & 2 & 1 \\
\hline 32 & EX5 & UK & O. mykiss & 1993 & O1 & 2 & 1 \\
\hline 32 & YRNC10 & USA & O. mykiss & 2003 & O1 & 2 & 3 \\
\hline 33 & $\mathrm{RD} 40$ & USA & O. mykiss & $\mathrm{nk}$ & O1 clonal group $5^{\mathrm{a}}$ & 1 & 3 \\
\hline 35 & RD88 & Denmark & O. mykiss & 1983 & O1 clonal group $5^{\mathrm{a}}$ & 1 & 3 \\
\hline 35 & RD120 & Italy & O. mykiss & $\mathrm{nk}$ & O1 clonal group $5^{\mathrm{a}}$ & 1 & 3 \\
\hline 36 & 06076 & Spain & O. mykiss & $\mathrm{nk}$ & $\mathrm{O} 1$ & 2 & 3 \\
\hline 39 & ATCC29473 & USA & O. mykiss & 1976 & O1 clonal group $5^{\mathrm{a}}$ & 1 & 3 \\
\hline 42 & RD28 & UK & O. mykiss & $\mathrm{nk}$ & $\mathrm{O}^{\mathrm{a}}$ & 1 & 2 \\
\hline 43 & RD20 & Finland & C. peled & $\mathrm{nk}$ & O1 clonal group $3^{a}$ & 1 & 2 \\
\hline
\end{tabular}

Transmission electron microscopy (TEM). Selected isolates were grown on TSA plates for $24 \mathrm{~h}$ at $22^{\circ} \mathrm{C}$. Cells were gently re-suspended in phosphate-buffered saline (PBS) to an optical density $\left(\mathrm{OD}_{650}\right)$ of 1.0 and fixed in $10 \%$ neutral buffered formalin. A $10 \mu \mathrm{l}$ drop of each suspension was placed onto a carbon-coated formvar grid and left for 1 min before being washed off the grid with $1 \%$ phosphotungstic acid. Excess stain was removed from the grids using wet filter paper and the grids were left to air dry. Grids were examined using a JEOL JEM 1210 TEM and digital images captured using a Gatan Erlangshen ES500W camera and Gatan Digital Micrograph software.

O-antigen serotyping. O-antigen serotyping of all isolates was performed by slide agglutination as described by Davies (1990).

SDS-PAGE of OMPs. OMP profiles of selected isolates were determined by sodium dodecyl sulphate polyacrylamide gel electrophoresis (SDS-PAGE) as described by Davies (1991b, Davies et al. 1992) using SE600 SDS-PAGE apparatus (Hoeffer).

PFGE. Isolates were grown on TSA plates for $48 \mathrm{~h}$ at $22^{\circ} \mathrm{C}$. Agarose plugs containing a suspension of Yersinia ruckeri genomic DNA were prepared according to the method described by Wagley et al. (2008). Briefly, Y. ruckeri genomic DNA was digested in situ using the restriction endonuclease NotI (100 U) for $5 \mathrm{~h}$ at $37^{\circ} \mathrm{C}$, with shaking at $100 \mathrm{rpm}$. A Salmonella braenderup molecular standard was prepared by the same method and restricted in situ with XbaI (Hunter et al.
2005). NotI digested agarose blocks were loaded into a $1 \%$ Bio-Rad PFGE-grade agarose gel and electrophoresed by the contour-clamped electric field method in $0.5 \times$ TBE buffer (with $200 \mathrm{mM}$ thiourea) using a Bio-Rad CHEF DRII apparatus (Hercules). Molecular standards were included in every sixth well. Run conditions were $6.0 \mathrm{~V} \mathrm{~cm}^{-1}$ with switch times of 1 to $15 \mathrm{~s}$ at $14^{\circ} \mathrm{C}$ for $18 \mathrm{~h}$. Images were captured using a Gel Doc 2000 gel documentation system (BioRad). Dendrograms and cluster analysis were performed using the BioNumerics version 4.6 software package (Applied Maths). Similarity analysis was performed using the Dice coefficient, and clustering was created using UPGMA. Bands above $30 \mathrm{kbp}$ were analysed, as smaller fragments could not be resolved accurately.

\section{RESULTS}

\section{Biotyping}

Biotyping was performed on all 160 isolates. All 52 of the serotype O1 rainbow trout isolates from the UK were shown to be biotype 2 (nonmotile and did not hydrolyse Tween 80). Eighty of the remaining 108 isolates were biotype 1. A single Spanish isolate (06076), US strain YRNC10, 2 French turbot isolates, and 18 Danish rainbow trout isolates were biotype 2, as were 5 serotype O1 UK Atlantic salmon isolates and a Norwegian serotype O5 Atlantic salmon isolate (Fig. 1). 


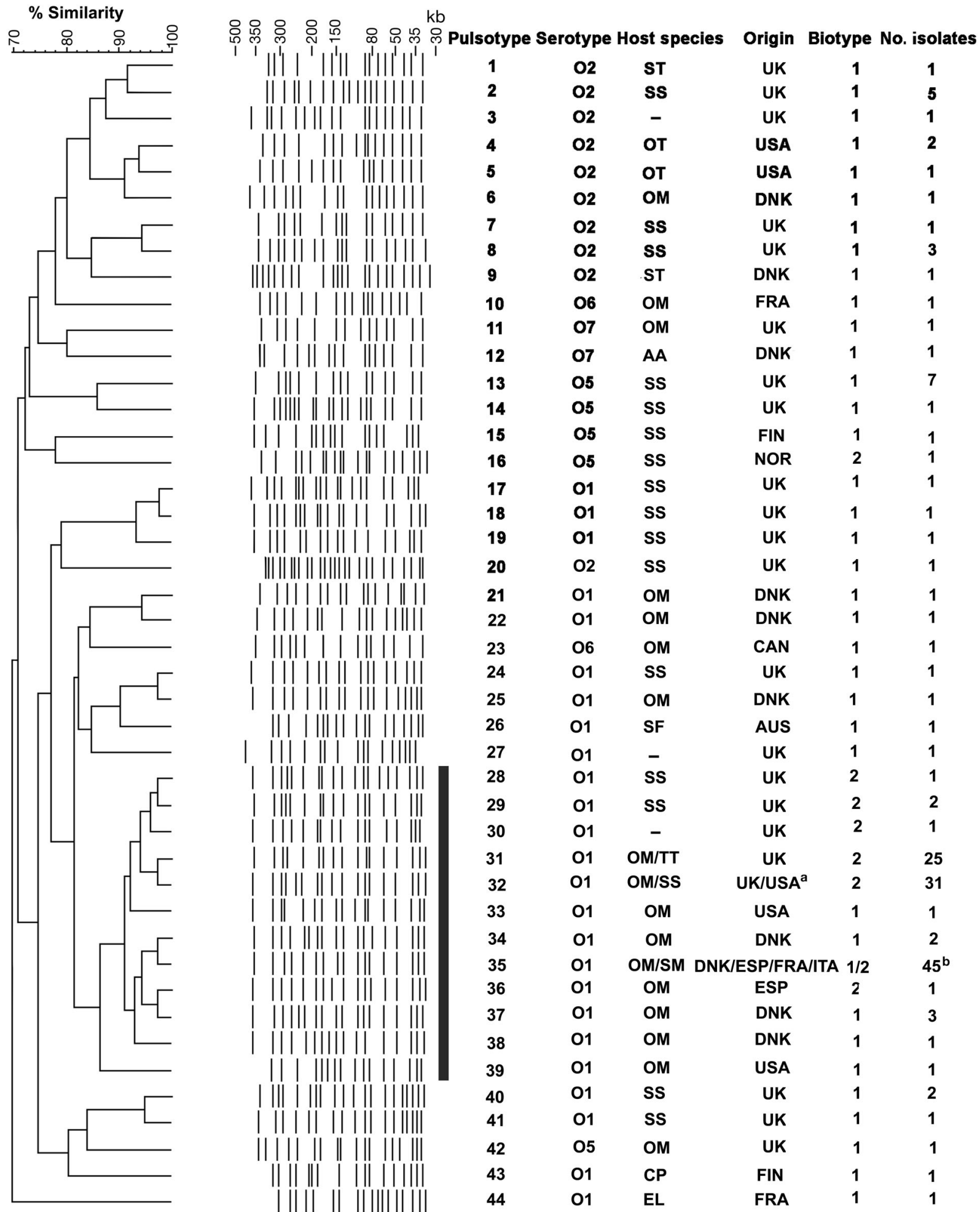

Fig. 1. Complete pulsed-field gel electrophoresis (PFGE) scheme. UPGMA-generated dendrogram showing pulsotypes clustered as percentage similarities produced using BioNumerics software (Applied Maths). For each group; pulsotype (pt), serotype, host species, origin, biotype and number of isolates are shown. Cluster of serotype O1 ATCC 29473 Hagerman type strain-like isolates indicated by the black vertical bar (pt28 to pt39). OM: Oncorynchus mykiss; SS: Salmo salar; ST: Salmo trutta; AA: Anguilla anguilla; CP: Coregonus peled; SM: Scophthalmus maximus; SF: Salvelinus fontinalis; EL: Esox lucius; OT: Onchorynchus tshawytscha; TT: Thymallus thymallus. CAN: Canada; DNK: Denmark; ESP: Spain; FRA: France; FIN: Finland; ITA: Italy; NOR: Norway. ${ }^{\text {a }} 30$ of the 31 isolates characterised as pt32 were from the UK; ${ }^{b}$ please refer to the text in the results section for a more detailed breakdown of the numbers, by biotype, country and species of origin, of the isolates characterised as pt35 


\section{Serotyping}

The majority (128) of tested isolates were serotype O1 (Fig. 1). Seventeen serotype O2 isolates, 11 serotype $\mathrm{O} 5$, and 2 each of serotypes $\mathrm{O} 6$ and $\mathrm{O} 7$ were also identified (Fig. 1).

\section{TEM}

Eight serogroup O1 biotype 2 isolates of Yersinia ruckeri were examined by TEM to confirm the absence of flagella, including representative isolates from Spain (isolate 06076; Table 2), the US (isolate YRNC10; Table 2), the UK (isolates RD10 and EX5; Table 2) and Denmark (isolates 970611/-2/2 and 030522-2/1, recovered from diseased rainbow trout in 1997 and 2003 respectively). In comparison, 2 biotype 1, motile, serogroup O1 isolates were also examined, a US isolate (RD40; Table 2) and one isolate (RD88; Table 2), and abundant flagella were generally observed, both projecting from the surfaces of the cells and as debris in the media surrounding the cells.

\section{OMP profiles}

OMP mobilities on SDS-PAGE were identical for 2 UK biotype 2 isolates (RD6 and EX5), and a US biotype 2 isolate YRNC10 (Fig. 2, Lanes 1, 3 and 5, respectively), consistent with OMP type 1 (Davies 1991b). However, there were in vitro differences in the expression of a $36 \mathrm{kDa}$ relatively abundant porin protein (Fig. 2, position A), which was abundant in RD6, but only weakly present in EX5 and YRNC10.

The OMP profile for the Spanish outbreak isolate (06076; Fig. 2, Lane 4) was identical to that of the ATCC 29473 Hagerman type strain (Fig. 2, Lane 8) and the European biotype 1 isolate (RD88; Fig. 2, Lane 2), RD88 having been previously identified as OMP type 3 (Davies 1991b). For comparative purposes, 2 recent UK Atlantic salmon isolates (a serotype O2 isolate, 07029; and a serotype $\mathrm{O} 1$ isolate, 07039; Fig. 2, Lanes 6 and 7 , respectively) were also analysed and had very similar profiles (OMP type 4; Table 2), which did not match the profiles of the rainbow trout isolates (Fig. 2).

\section{PFGE}

PFGE characterisation of the 160 isolates revealed 44 different pulsotypes (Fig. 1). PFGE successfully discriminated between all reference strains from the Davies (1991a) scheme (Fig. 1; Table 2) within previously designated clonal groups, based on serotype,

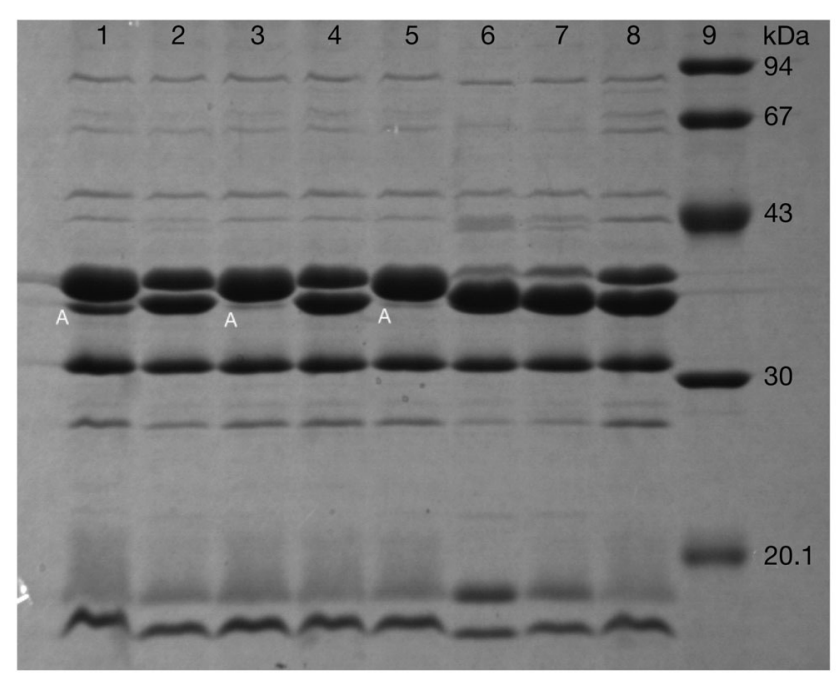

Fig. 2. Yersinia ruckeri. Outer membrane protein (OMP) profiles of enterobacterium isolates from Oncorhynchus mykiss and Salmo salar after heat treatment at $80^{\circ} \mathrm{C}$. Lane 1: strain RD6 (UK biotype 2 pt31 strain); Lane 2: isolate RD88 (European pt35 serotype O1 clonal group 5 isolate); Lane 3: isolate EX5 (pt32 serotype O1 biotype 2 strain); Lane 4: isolate 06076 (Spanish pt36 biotype 2 strain); Lane 5: strain YRNC10 (US rainbow trout pt32 biotype 2 strain); Lane 6: isolate 07029 (UK Atlantic salmon pt8 serotype O2 strain); Lane 7: isolate 07039 (UK Atlantic salmon pt19 serotype O1 strain); Lane 8: ATCC 29473 Hagerman type strain (pt39); Lane 9: molecular weight standard (Pharmacia). pt: pulsotype as assigned in Fig. 1. A: the position of the $36 \mathrm{kDa}$ porin protein

biotype and OMP type (Table 2). Isolates belonging to the same previously assigned clonal groups generally had identical or similar pulsotypes, and were mostly clustered together based on UPGMA.

\section{Rainbow trout isolates}

UK, European and US serotype O1 isolates known to be virulent for rainbow trout were shown to be genetically very similar by PFGE, forming a distinct subgroup of pulsotypes (pt31 to pt39; Fig. 1). Within this group, European isolates (pt34 to pt38) clustered separately from UK isolates (pt31 and pt32; Figs. 1 \& 3). Eighteen UK rainbow trout field isolates tested from 1981 to 1992 were pt31, including an isolate recovered as part of the investigation linked to the first confirmed outbreak of the disease in 1981 in England (Roberts 1983) and isolates characterised previously by Davies (1991a) as representatives of serotype O1 clonal group 2 (Table 2). From 1993 to 2006, the majority (24 out of 33) of tested rainbow trout field isolates had pulsotypes matching that of isolate EX5 isolated in 1993 (pt32, Austin et al. 2003). Pt31 and pt32 were nearly identical, the difference being the presence of a single additional 
band of $240 \mathrm{~kb}$ in the profile of pt32 (Figs. 1 \& 3). The ATCC 29473 Hagerman type strain (pt39) had a lower homology to the main pathogenic group (86\%) and clustered separately from European and other US O1 clonal group 5 isolates examined by UPGMA (Figs. 1 \& 3).

Other European, USA and UK rainbow trout isolates had an even higher degree of homology (>90\% by UPGMA). USA and European isolates covering pt33 to pt37 differed from UK pt31 and pt32 isolates, most notably by the degree of separation between 3 large fragments ranging from 300 to $250 \mathrm{~kb}$, but had similar restriction fragment profiles between 180 and $125 \mathrm{~kb}$ (Fig. 1). US isolate YRNC10 recovered in 2003 had the same pulsotype as isolate EX5 (pt32; Fig. 3; Table 2). This US isolate also had the same serotype, biotype and OMP profile as EX5 (Table 2; Fig. 2). This was the only example of a characteristic UK-like isolate being identified outside the UK. No UK-like pulsotypes were detected in mainland Europe.

\section{pt35 and pt36 isolates}

The majority ( $\mathrm{n}=43 / 56$ ) of European rainbow trout field isolates tested were pt35 (Figs. 1 \& 3), including Italian and Danish reference isolates (RD88 and RD120), previously characterised by Davies (1991a) as representatives of serotype O1 clonal group 5 (Table 2).

Of the Danish rainbow trout isolates examined, 39/50 were characterised as pt35. Danish pt35 isolates recovered in or before $1994(\mathrm{n}=10)$ were all biotype 1 , which Davies (1991a) previously associated with serotype O1 clonal group 5 isolates. Following the first recovery of a pt35/biotype 2 isolate in 1995, pt35/biotype 2 Danish isolates then became increasingly identified. Five of 14 pt35 isolates recovered from rainbow trout between 1995 and 1999 were biotype 2, while 13 of 15 pt35 isolates examined after this time were biotype 2. Two biotype 2 isolates of Yersinia ruckeri isolated from French turbot were also shown to be pt35. The serotype $\mathrm{O} 1$ biotype 2 Spanish isolate had a unique pulsotype, pt 36 (Figs. 1 \& 3). All the other isolates recovered from rainbow trout were biotype 1 , including the type strain of the species, and 1 French and 2 Spanish pt35 field isolates.

\section{Atlantic salmon isolates}

Unlike isolates from farmed UK rainbow trout, a diverse range of Yersinia ruckeri isolates were recovered from UK Atlantic salmon. Fourteen pulsotypes

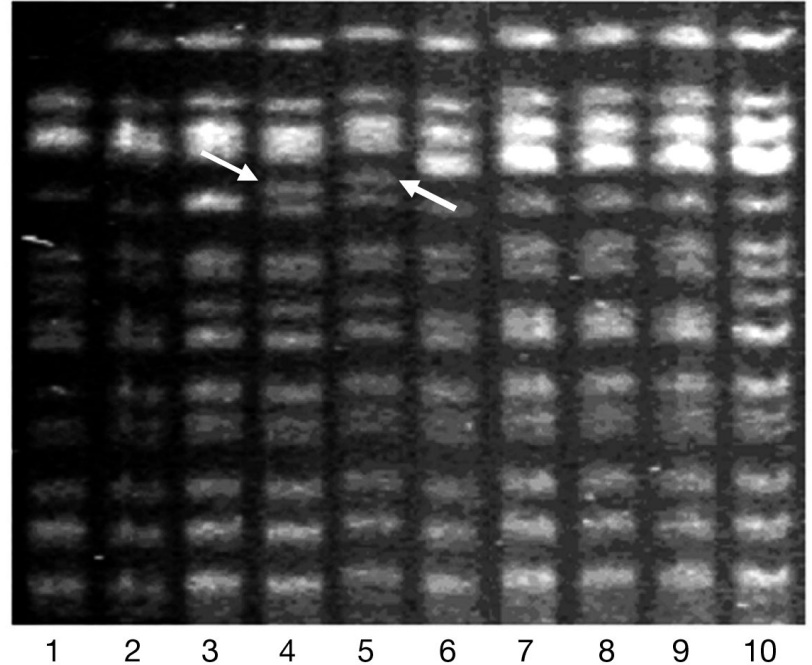

Fig. 3. Yersinia ruckeri. Pulsed-field gel electrophoretogram ( $1 \%$ agarose) of a selection of NotI digests of biotypes 1 and 2 serotype O1 Y. ruckeri isolates recovered from Oncorhynchus mykiss. Lane 1: ATCC 29473 Hagerman type strain (pt39); Lane 2: US biotype 1 pt33 strain RD40; Lane 3: UK biotype 2 pt31 strain RD10; Lane 4: UK serotype O1 biotype 2 pt32 strain EX5; Lane 5: US biotype 2 pt32 strain YRNC10; Lane 6: Danish biotype 1 pt35 motile strain RD88; Lane 7: Spanish biotype 1 pt35 strain 06077 ; Lane 8: Danish biotype 2 pt35 isolate 970611/-2/2; Lane 9: Danish biotype 2 pt 35 isolate 030522-2/1; Lane 10: Spanish biotype 2 pt36 isolate 06076. pt: pulsotype as assigned in Fig. 1. Additional information on isolates ATCC29473, EX5, YRNC10, RD10, RD40, RD88, 06076 are indicated in Table 2. Danish strains 900530/1/1, 970611/$2 / 2,98680551 / 12 \mathrm{~A}$ and $030522-2 / 1$ were recovered in 1990, 1997, 1998 and 2003, respectively. Arrows indicate additional $240 \mathrm{~kb}$ bands in isolates EX5 and YRNC10

were identified among the $34 \mathrm{Y}$. ruckeri isolates from farmed Atlantic salmon (Fig. 4). These isolates largely clustered into 3 major groups based on serotype (O1, $\mathrm{O} 2$ and O5). The serotype $\mathrm{O} 5$ isolates mostly clustered together (Group 2) and had greater homology to each other than to serotypes $\mathrm{O} 1$ and $\mathrm{O} 2$ isolates. The major serotype O1 cluster further split into 2 groups (1a and 1b; Fig. 4), one of which (Group 1a) containing motile isolates recovered between 1999 and 2006 (pts17, 18 and 19; Fig. 4). The second group (Group 1b) comprised nonmotile organisms isolated between 1986 and 1999 (pts28, 29 and 32; Fig. 4). The nonmotile serotype O1 pts28 and 29 isolates shared high homology (94\%) with UK pts31 and 32 rainbow trout isolates. Two biotype 2 pt32 isolates were also recovered from Atlantic salmon in 1999 (Fig. 4). The restriction patterns of the remaining serotypes $\mathrm{O} 2, \mathrm{O} 5, \mathrm{O} 6$ and $\mathrm{O} 7$ isolates, from salmon as well as other species, formed no distinct clusters (Fig. 1; Fig. 4, Group 3). 


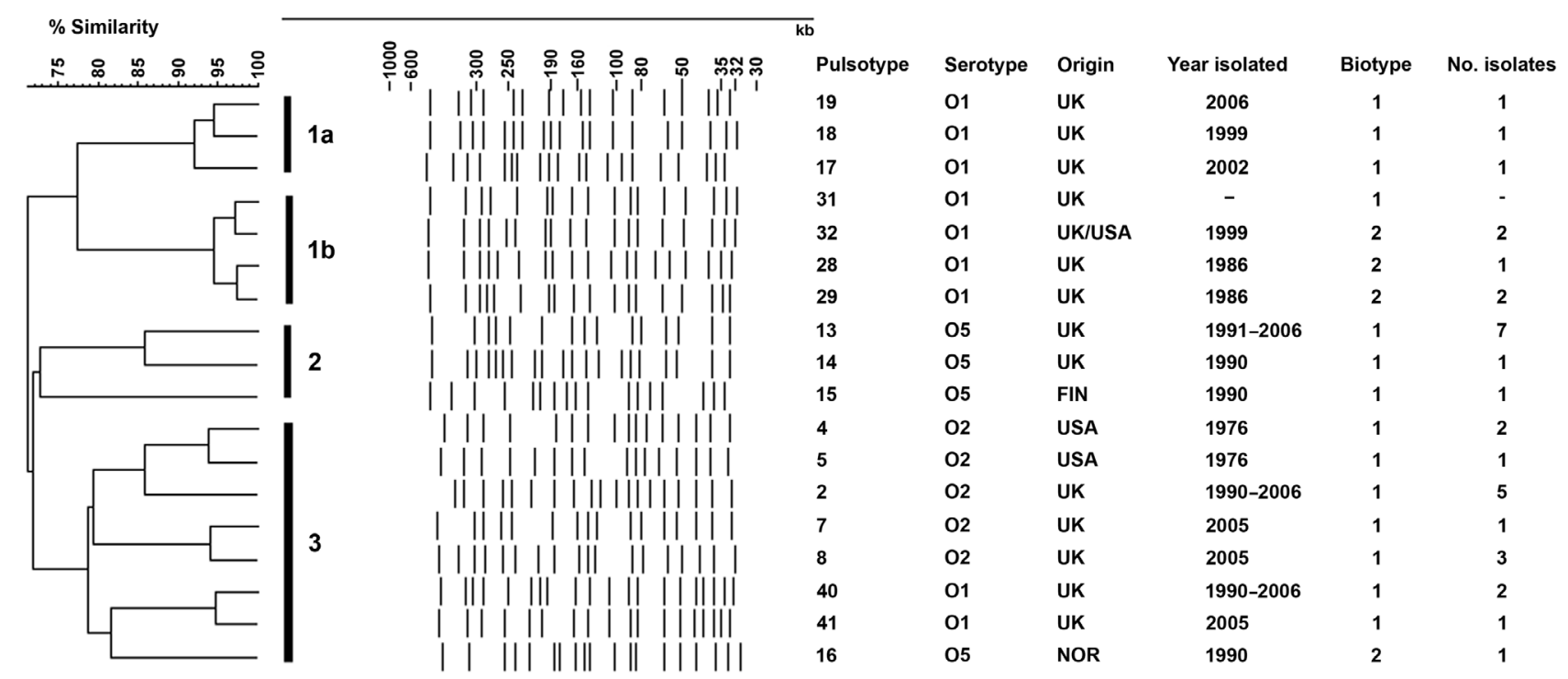

Fig. 4. Yersinia ruckeri. UPGMA-generated dendrogram showing pulsotypes of strains found in Salmo salar clustered as percentage similarities. Data were analysed and the image produced using BioNumerics software (Applied Maths). Pulsotype (pt), serotype, country of origin, year isolated, biotype and number of isolates in group are shown. Pt31 was only found in UK rainbow trout but its profile is included for comparative purposes, as well as the profiles of pts4 and 5, which were observed only in US Chinook salmon isolates. The 4 major groupings of pulsotypes identified, based on clustering by UPGMA, are indicated (1a, 1b, 2 and 3) NOR: Norway; FIN: Finland

\section{DISCUSSION}

In general, the highly clonal nature of Yersinia ruckeri isolates responsible for ERM in rainbow trout, as shown by this and other studies (Pyle et al. 1987, Davies 1991a, Garcia et al. 1998), is similar to that observed for other significant bacterial pathogens of farmed fish (Grayson et al. 1999, Eyngor et al. 2004, Reid et al. 2004, Nash et al. 2006). Although the isolates analysed were geographically biased and, in many cases, nonrandomly selected (e.g. reference isolates), a number of other interesting epidemiological associations and trends can be discerned.

Yersinia ruckeri was likely first introduced to the European rainbow trout aquaculture industry from the US in the late 1970s to the early 1980s (Horne \& Barnes 1999). However, pulsotyping confirmed the earlier observations of Davies (1991a) that UK and European serotype O1 isolates causing ERM in rainbow trout formed distinct, non-overlapping subpopulations. These subpopulations had greater homology to US isolates than to each other, suggesting that $Y$. ruckeri was introduced separately into the UK and Europe from the USA and subsequent cross-border transfer of UK and European isolates has been limited.

There have been a series of recent reports of outbreaks of ERM caused by Yersinia ruckeri biotype 2 isolates (Austin et al. 2003, Fouz et al. 2006, Arias et al. 2007). This study shows that the emergence and dissemination of these isolates is complicated. The majority of ERM-causing serotype $\mathrm{O} 1$ isolates in the UK has always been biotype 2 (Davies \& Frerichs 1989, present study). In contrast, Danish biotype 2 serotype O1 isolates shared the same pulsotype (pt35) as the serotype O1 biotype 1 clone (clonal group 5), the latter being responsible for the majority of disease outbreaks since the first emergence of ERM in Denmark and elsewhere in mainland Europe (Davies 1991a). It is therefore likely that the Danish biotype 2 isolates have independently emerged out of the existing mainland European Y. ruckeri population, rather than representing cross-border transfer of UK biotype 2 isolates into or from Denmark. As the Spanish biotype 2 isolate 06076 had a different pulsotype (pt36) from the Danish biotype 2 (pt35) isolates examined (Fig. 4), it may well have emerged separately out of circulating pt35 Spanish isolates. Together, the data suggest that the biotype 2 phenotype has arisen independently in different clonal groups in mainland Europe and the UK.

The biotype 2 pt32 isolate EX5, described by Austin et al. (2003), can be distinguished by PFGE from earlier UK biotype 2 (pt31) isolates. Pt32 isolates were also largely responsible for ERM outbreaks among rainbow trout investigated by the Cefas Weymouth Laboratory over the last 5 to 7 yr. Further work is required to experimentally confirm the extent to which pt32 isolates possess characteristics (e.g. increased virulence, or survival capacity) that favour their selection over pt31 isolates. Although there were observed differ- 
ences in levels of in vitro expression of a $36 \mathrm{kDa}$ porin protein between the $2 \mathrm{pt} 31$ and the pt32 isolates examined (Fig. 2), it should not be assumed at this stage that this is an additional consistent differentiating characteristic. Davies (1991b) also noted differences in expression levels of this protein in isolates that were circulating in the UK prior to 1986.

It has been suggested that the biotype 2 phenotype may confer a selective advantage due to loss of flagellar antigens in vaccinated fish (Fouz et al. 2006). The observation that lack of motility was also always associated with lack of ability to hydrolyse Tween 80 could be explained by studies which have shown that secretion of a phospholipase virulence factor (YplA) by a related species, Yersinia enterocolitica, is dependent on a competent flagellar type III secretion apparatus (Young et al. 1999). In that study, no YplA production was detected in isolates carrying mutations in a range of different flagellar assembly genes. It is therefore possible that mutations to analagous flagellar secretion genes in $Y$. ruckeri could result in loss of motility and associated loss of phospholipase secretion.

As to the Scottish Atlantic salmon isolates characterised, the data suggest that rainbow trout isolates have infected this species in the past. However, other more modern isolates were not homologous to serotype $\mathrm{O} 1$ rainbow trout isolates, indicating that they may have emerged or have been introduced separately. These isolates were reportedly obtained from fish displaying clinical signs of the disease, suggesting that isolates of serotypes $\mathrm{O} 1, \mathrm{O} 2$ and $\mathrm{O} 5$ are virulent to Atlantic salmon. Discussions with Scottish fish farming companies revealed that, coinciding with the emergence of these novel isolates, the vaccines used to immunise salmon fry have had to be modified to include these additional antigens to maintain effective protection against ERM (T. Laidler pers. comm.).

Strain replacement in response to continuous immunisation selective pressure has been reported for other fish pathogens (Bachrach et al. 2001) and medically important bacteria (e.g. Urwin et al. 1996, Spratt \& Greenwood 2000, Hallander et al. 2005). This may have also occurred with biotype 2 Yersinia ruckeri isolates infecting rainbow trout in Denmark, Spain, the US and the UK, as well as isolates affecting Atlantic salmon.

Further work is required to determine the in vivo biological significance of the genetic, serological and physiological differences observed in vitro in rainbow trout serotype $\mathrm{O} 1$ biotypes 1 and 2 isolates, and in Atlantic salmon serotypes O1, O2 and O5 isolates. This should include investigation of the extent to which vaccines prepared with antigens from different isolates genuinely differ in cross protectiveness in both species, as well as virulence studies. In particular, experimental confirmation that recent isolates from Atlantic salmon have increased in virulence is required. Such information would benefit the development of improved vaccines that give effective cross-protection against the range of pathogenic isolates that species are likely to encounter.

Acknowledgements. We thank D. Austin (Heriot-Watt University, Edinburgh, Scotland), T. Laidler (Marine Harvest, Lochailort, Scotland), T. Wallis (Ridgeways Biologicals), S. Tops (Schering Plough Animal Health) and C. Michel (Institut National de la Recherche Agronomique, France) for the generous provision of isolates that were used in the study. E. Roberts and K. Clarke provided valuable technical assistance. The work was funded by the UK Department for Environment, Food and Rural Affairs (Defra) through Project FC1178 and through a placement year studentship (FC1172) to R.W.W.

\section{LITERATURE CITED}

Arias CR, Olivares-Fuster O, Hayden $\mathrm{H}$, Shoemaker CA, Grizzle JM, Clesius PH (2007) First report of Yersinia ruckeri biotype 2 in the USA. J Aquat Anim Health 19:35-40

Austin DA, Robertson PAW, Austin B (2003) Recovery of a new biogroup of Yersinia ruckeri from diseased rainbow trout Oncorhynchus mykiss (Walbaum). Syst Appl Microbiol 26:127-131

Bachrach G, Zlotkin A, Hurvitz A, Evans DL, Eldar A (2001) Recovery of Streptococcus iniae from diseased fish previously vaccinated with a streptococcus vaccine. Appl Environ Microbiol 67:3756-3758

> Bravo S, Midtlyng PJ (2007) The use of fish vaccines in the Chilean salmon industry 1999-2003. Aquaculture 270: $36-42$

Bruno DW, Munro ALS (1989) Immunity in Atlantic salmon Salmo salar L. fry following vaccination against Yersinia ruckeri, and the influence of body weight and infectious pancreatic necrosis virus (IPNV) on the detection of carriers. Aquaculture 81:205-211

Buller NB (2004) Bacteria from fish and other aquatic animals: a practical identification manual. CABI Publishing, Wallingford

Bullock GL, Stuckey HM, Herman RL, Smith CE (1976) Comparative susceptibility of Atlantic salmon Salmo salar to the enteric redmouth bacterium and Aeromonas salmonicida. J Wildl Dis 12:376-379

Cowan ST, Steel KJ (1993) Cowan and Steel's manual for the identification of medical bacteria, 3rd edn. Cambridge University Press, Cambridge

Daly JG, Lindvik B, Stevenson RMW (1986) Serological heterogeneity of recent isolates of Yersinia ruckeri from Ontario and British Columbia. Dis Aquat Org 1:151-153

Davies RL (1990) O-serotyping of Yersinia ruckeri with special emphasis on European isolates. Vet Microbiol 22: 299-307

> Davies RL (1991a) Clonal analysis of Yersinia ruckeri based on biotypes, serotypes and outer membrane protein types. J Fish Dis 14:221-228

> Davies RL (1991b) Outer membrane protein profiles of Yersinia ruckeri. Vet Microbiol 26:125-140 
Davies RL (1991c) Virulence and serum-resistance in different clonal groups and serotypes of Yersinia ruckeri. Vet Microbiol 29:289-297

Davies RL, Frerichs GN (1989) Morphological and biochemical differences among isolates of Yersinia ruckeri obtained from wide geographical areas. J Fish Dis 12:357-365

Davies RL, Parton R, Coote JG, Gibbs HA, Freer JH (1992) Outer-membrane protein and lipopolysaccharide variation in Pasteurella haemolytica serotype A1 under different growth conditions. J Gen Microbiol 138:909-922

Eyngor M, Zlotkin A, Ghittino C, Prearo M, Douet DG, Chilmonczyk S, Eldar A (2004) Clonality and diversity of the fish pathogen Lactococcus garvieae in Mediterranean countries. Appl Environ Microbiol 70:5132-5137

Fouz B, Zarza C, Amaro C (2006) First description of nonmotile Yersinia ruckeri serovar I strains causing disease in rainbow trout Oncorhynchus mykiss (Walbaum) cultured in Spain. J Fish Dis 29:339-346

Garcia JA, Dominguez L, Larsen JL, Pedersen K (1998) Ribotyping and plasmid profiling of Yersinia ruckeri. J Appl Microbiol 85:949-955

Grayson TH, Cooper LF, Atienzar FA, Knowles MR, Gilpin ML (1999) Molecular differentiation of Renibacterium salmoninarum isolates from worldwide locations. Appl Environ Microbiol 65:961-968

Guilvout I, Quilici ML, Rabot S, Lesel R, Mazigh D (1988) BamHI restriction endonuclease analysis of Yersinia ruckeri plasmids and their relatedness to the genus Yersinia 42- to 47-megadalton plasmid. Appl Environ Microbiol 54:2594-2597

Hallander HO, Advani A, Donnelly D, Gustafsson L, Carlsson RM (2005) Shifts of Bordetella pertussis variants in Sweden from 1970 to 2003, during three periods marked by different vaccination programs. J Clin Microbiol 43: $2856-2865$

Hardy RW, Fornshell GCG, Brannon EL 2000. Rainbow trout culture. In: Stickney RR (ed) Encyclopaedia of aquaculture. Wiley Interscience, New York, p 716-722

Horne MT, Barnes AC (1999) Enteric redmouth disease (Yersinia ruckeri). In: Woo PTK, Bruno DW (eds) Fish diseases and disorders, Vol 3. Viral, bacterial and fungal infections. CABI Publishing, Wallingford, p 445-477

Editorial responsibility: David Bruno, Aberdeen, UK
Hunter SB, Vauterin P, Lambert-Fair MA, Van Duyne MS and others (2005) Establishment of a universal size standard strain for use with the PulseNet standardized pulsed-field gel electrophoresis protocols: converting the national databases to the new size standard. J Clin Microbiol 43: 1045-1050

Nash JHE, Findlay WA, Luebbert CC, Mykytczuk OL and others (2006) Comparative genomics profiling of clinical isolates of Aeromonas salmonicida using DNA microarrays. BMC Genomics 7:43

Parson MB, Cooper KLF, Kubota KA, Puhr N and others (2007) PulseNet USA standardized pulsed-field gel electro-phorensis protocol for subtyping of Vibrio parahaemolyticus. Foodborne Pathog Dis 3:285-292

Pyle SW, Ruppenthal T, Cipriano RC, Shotts EB (1987) Further characterization of biochemical and serological characteristics of Yersinia ruckeri from different geographic areas. Microbios Lett 35:87-93

Reid HI, Griffen AA, Birkbeck TH (2004) Isolates of Piscirickettsia salmonis from Scotland and Ireland show evidence of clonal diversity. Appl Environ Microbiol 70:4393-4397

Roberts MS (1983) A report of an epizootic in hatchery reared rainbow trout Salmo gairdneri Richardson, at an English trout farm, caused by Yersinia ruckeri. J Fish Dis 6:551-552

> Schill WB, Phelps SR, Pyle SW (1984) Multilocus electrophoretic assessment of the genetic structure and diversity of Yersinia ruckeri. Appl Environ Microbiol 48: 975-979

Spratt BG, Greenwood B (2000) Prevention of pneumococcal disease by vaccination: Does serotype replacement matter? Lancet 356:1210-1211

Stevenson RMW, Airdrie DW (1984) Serological variation among Yersinia ruckeri strains. J Fish Dis 7:247-254

> Urwin G, Krohn J, Deaver-Robinson K, Wenger J, Farley M (1996) Invasive disease due to Haemophilus influenzae serotype f: clinical and epidemiological characteristics in the $H$. influenzae serotype B vaccine era. Clin Infect Dis 22:1069-1076

Young GM, Schmeil DH, Miller VL (1999) A new pathway for the secretion of virulence factors by bacteria: The flagellar export apparatus functions as a protein-secretion system. Proc Natl Acad Sci USA 96:6456-6461

Submitted: September 5, 2008; Accepted: January 25, 2009

Proofs received from author(s): February 27, 2009 